\title{
Time for a Time Window Extension: Insights from Late Presenters in the ESCAPE Trial
}

\author{
(D).W. Evans, (D)B.R. Graham, (DP. Pordeli, (DF.S. Al-Ajlan, (DR. Willinsky, (D).J. Montanera, (D).L. Rempel, (D) A. Shuaib, (D) P. Brennan, \\ (DD. Williams, (DD. Roy, (D)A.Y. Poppe, DT.G. Jovin, DT. Devlin, DB.W. Baxter, (D)T. Krings, (D)F.L. Silver, (DD.F. Frei, DC. Fanale, \\ (DD. Tampieri, (D). Teitelbaum, (DD. lancu, (D). Shankar, (D)P.A. Barber, (D)A.M. Demchuk, (DM. Goyal, (D) M.D. Hill, and (DB.K. Menon; \\ for the ESCAPE Trial Investigators
}

\begin{abstract}
BACKGROUND AND PURPOSE: The safety and efficacy of endovascular therapy for large-artery stroke in the extended time window is not yet well-established. We performed a subgroup analysis on subjects enrolled within an extended time window in the Endovascular Treatment for Small Core and Proximal Occlusion Ischemic Stroke (ESCAPE) trial.
\end{abstract}

MATERIALS AND METHODS: Fifty-nine of 315 subjects ( 33 in the intervention group and 26 in the control group) were randomized in the ESCAPE trial between 5.5 and 12 hours after last seen healthy (likely to have groin puncture administered 6 hours after that). Treatment effect sizes for all relevant outcomes (90-day mRS shift, mRS 0-2, mRS 0-1, and 24-hour NIHSS scores and intracerebral hemorrhage) were reported using unadjusted and adjusted analyses.

RESULTS: There was no evidence of treatment heterogeneity between subjects in the early and late windows. Treatment effect favoring intervention was seen across all clinical outcomes in the extended time window (absolute risk difference of 19.3\% for mRS 0-2 at 90 days). There were more asymptomatic intracerebral hemorrhage events within the intervention arm (48.5\% versus $11.5 \%, P=.004)$ but no difference in symptomatic intracerebral hemorrhage.

CONCLUSIONS: Patients with an extended time window could potentially benefit from endovascular treatment. Ongoing randomized controlled trials using imaging to identify late presenters with favorable brain physiology will help cement the paradigm of using time windows to select the population for acute imaging and imaging to select individual patients for therapy.

ABBREVIATION: ICH = intracerebral hemorrhage

C

urrent guidelines recommend endovascular treatment in patients with ischemic stroke presenting within 6 hours from stroke-symptom onset. ${ }^{1}$ One guideline allows treatment of selected patients in the 6- to 12 -hour window. ${ }^{2}$ A meta-

Received April 17, 2017; accepted after revision August 15.

From the Departments of Clinical Neurosciences and Radiology (J.W.E., B.R.G., F.S.A.-A., P.A.B., A.M.D., M.G., M.D.H., B.K.M.) and Community Health Sciences and Department of Medicine (P.P., M.D.H., B.K.M.), Cumming School of Medicine, University of Calgary, Calgary, Alberta, Canada; Department of Medical Imaging (R.W. W.J.M.), Division of Radiology (T.K.), and Division of Neurology (F.L.S., C.F.), Department of Medicine, University Health Network, Toronto Western Hospital, Toronto, Ontario, Canada; Departments of Radiology (J.L.R.) and Medicine (Neurology) (A.S.), University of Alberta, Edmonton, Alberta, Canada; Departments of Neuroradiology (P.B.) and Geriatric and Stroke Medicine (D.W.), Beaumont Hospital and the Royal College of Surgeons in Ireland, Dublin, Ireland; Departments of Radiology (D.R.) and Neurosciences (A.Y.P.), Centre hospitalier de l'Université de Montréal, University of Montreal, Montreal, Quebec, Canada; Department of Neurology (T.G.J.), University of Pittsburgh Medical Center, Pittsburgh, Pennsylvania; Erlanger Medical Centre (T.D.) and Department of Radiology (B.W.B), Erlanger Hospital, University of Tennessee, Chattanooga, Tennessee; Colorado Neurological Institute (D.F.F., D.T.), Engelwood, Colorado; Montreal Neurological Institute (J.T.), McGill University, Montreal, Quebec, Canada; Department of Radiology (D.I.), The Ottawa Hospital, University of Ottawa, Ottawa, Ontario, Canada; Department of Neuroradiology (J.S.), Dalhousie University, Halifax, Nova Scotia, Canada; Hotchkiss Brain Institute (P.A.B., A.M.D., M.G., M.D.H., B.K.M.), University of Calgary, Calgary, Alberta, Canada; and Foothills Medical Centre (B.K.M.), Calgary, Alberta, Canada. analysis of the recent endovascular trials performed by the Highly Effective Reperfusion Evaluated in Multiple Endovascular Stroke trials (HERMES) collaboration showed the highest benefit of endovascular treatment among patients present-

The study sponsor was the University of Calgary. Covidien provided major funding through an unrestricted grant to the University of Calgary. Additional active and in-kind support for the trial was from a consortium of funding public and charitable sources (Heart and Stroke Foundation Canada, Alberta Innovates Health Solutions, Alberta Health Services, Canadian Stroke Prevention Intervention Network through Canadian Institutes of Health Research) and the University of Calgary (Hotchkiss Brain Institute, Department of Clinical Neurosciences, Department of Radiology, and Calgary Stroke Program).

The sponsor of the trial was the Governors of the University of Calgary. The sponsor had no role in the design, data gathering, analysis, or reporting of the trial. The University of Calgary received unrestricted grants from Medtronic (Covidien), Alberta Innovates Health Solutions, Heart and Stroke Foundation Canada, Canadian Institute for Health Research through the Canadian Stroke Prevention Intervention Network, and Alberta Health Services. The University of Calgary provided internal funding from the Hotchkiss Brain Institute, the Department of Clinical Neurosciences, and Department of Radiology.

Clinical Trial Registration: www.clinicaltrials.gov NCT01778335.

Please address correspondence to Bijoy K. Menon, MD, MSc, Foothills Medical Centre, 1403 29th St NW, Calgary, AB T2N 2T9, Canada; e-mail: docbijoymenon@gmail.com

- Indicates open access to non-subscribers at www.ajnr.org

http://dx.doi.org/10.3174/ajnr.A5462 
Table 1: Baseline characteristics and workflow in subjects with last seen healthy to randomization time $>5.5$ hours

\begin{tabular}{|c|c|c|}
\hline & $\begin{array}{l}\text { Intervention } \\
\quad(n=33)\end{array}$ & $\begin{array}{l}\text { Control } \\
(n=26)\end{array}$ \\
\hline \multicolumn{3}{|l|}{ Demographics } \\
\hline Age (median) (IQR) (yr) & $66.1(15.2)$ & $67.9(21.9)$ \\
\hline Female sex & $60.6 \%(20)$ & $42.3 \%(11)$ \\
\hline Caucasian race & $87.9 \%(29)$ & $92.3 \%(24)$ \\
\hline \multicolumn{3}{|l|}{ Medical history } \\
\hline Hypertension & $66.7 \%(22)$ & $80.8 \%(21)$ \\
\hline Diabetes mellitus & $15.2 \%(5)$ & $26.9 \%(7)$ \\
\hline Atrial fibrillation & $42.4 \%(14)$ & $42.3 \%(11)$ \\
\hline \multicolumn{3}{|l|}{ Clinical characteristics } \\
\hline NIHSS score (median) (IQR) & $14(4)$ & $17(12)$ \\
\hline $\begin{array}{l}\text { Systolic blood pressure at hospital arrival (median) (IQR) } \\
\text { (mm Hg) }\end{array}$ & $143(22)$ & $138(43)$ \\
\hline Serum glucose at hospital arrival (median) (IQR) (mmol/L) & $6.8(2.2)$ & $6.9(2.0)$ \\
\hline \multicolumn{3}{|l|}{ Imaging characteristics } \\
\hline ASPECTS on baseline noncontrast CT (median) (IQR) & $9(2)$ & $8.5(3)$ \\
\hline \multicolumn{3}{|l|}{ Location of occlusion on CTA ${ }^{a}$} \\
\hline ICA with involvement of the MI MCA segment $(n=16)$ & $29.0 \%(9 / 31)$ & $26.9 \%(7 / 26)$ \\
\hline M1 or all M2 MCA segments $(n=40)$ & $67.7 \%(21 / 31)$ & $73.1 \%(19 / 26)$ \\
\hline Single M2 MCA segment $(n=1)$ & $3.2 \%(1 / 31)$ & $0 \%(0 / 26)$ \\
\hline \multicolumn{3}{|l|}{ Process time (min) } \\
\hline Stroke onset to randomization (median) (IQR) & $468(179)$ & 405 (107) \\
\hline \multicolumn{3}{|l|}{ Treatment } \\
\hline IV alteplase & $24.2 \%(8 / 33)$ & $57.8 \%(15 / 26)$ \\
\hline
\end{tabular}

on CT angiography. ${ }^{6,8}$ Because the 75th percentile for randomization to arterial access/groin puncture time was 28 minutes in the intervention group, patients randomized between 5.5 and 12 hours from last seen healthy (likely to undergo arterial access/groin puncture $>6$ hours from symptom onset/last seen healthy) were defined as the extended time window population for the current analyses.

The primary outcome was the modified Rankin Scale score at 90 days after stroke onset. Secondary outcomes were mRS 0-2, mRS 0-1 (all at 90 days), the proportion achieving NIHSS $0-2$ at 24 hours, and the proportion developing intracerebral hemorrhage $(\mathrm{ICH})$, reported both as symptomatic ICH and using the European Cooperative Acute Stroke Study 2 (ECASS 2) categories on follow-up imaging. ${ }^{9}$ Reperfusion (modified TICI $2 \mathrm{~b}-3$ ) is reported for the intervention arm. Data are summarized using descriptive statistics, and the adjusted

ing within 5 hours; however, a smaller benefit was seen in those presenting after 5 hours of symptom onset, with most of these patients presenting $<8$ hours after onset. ${ }^{3}$ Another individual patient-level meta-analysis from the first 5 trials reported a benefit of endovascular therapy over standard medical therapy when arterial puncture was performed $<7.3$ hours from symptom onset. ${ }^{4}$

Currently, Endovascular Therapy Following Imaging Evaluation for Acute Ischemic Stroke 3 (DEFUSE 3) and Clinical Mismatch in the Triage of Wake Up and Late Presenting Strokes Undergoing Neurointervention with Trevo (DAWN) are 2 major multicenter randomized trials assessing the possible benefit of endovascular treatment in image-selected patients presenting in late time windows (6-24 hours in DAWN and 6-16 hours in DEFUSE 3). The recent presentation of positive data from the DAWN study highlights the importance of imaging in the selection of late-presenting patients. ${ }^{5}$ The Endovascular Treatment for Small Core and Proximal Occlusion Ischemic Stroke (ESCAPE) trial used head CT and CT angiography as radiographic markers to enroll patients up to 12 hours from symptom onset (defined as the last known well time), thus providing a unique perspective on patients presenting to medical attention relatively late. We analyzed data from patients in the extended timeframe (6-12 hours) of the ESCAPE trial. ${ }^{6}$

\section{MATERIALS AND METHODS}

Data are from the ESCAPE trial. The ESCAPE trial was a prospective, multicenter, randomized, controlled, open-label trial design with blinded outcome assessment. ${ }^{6,7}$ The trial enrolled patients presenting within 12 hours from last seen healthy with disabling ischemic stroke, a small core infarct on noncontrast head CT (ASPECTS 6-10), and moderate-to-good collaterals outcomes were assessed using both ordinal logistic regression and unconditional logistic regression with adjustment for key prognostic variables (age, sex, baseline NIHSS score, baseline site of occlusion, baseline NCCT ASPECTS, and intravenous alteplase treatment). Interaction was assessed using a likelihood ratio test within the logistic regression analysis with a multiplicative interaction term.

\section{RESULTS}

Fifty-nine of 315 (19\%) subjects were randomized $>5.5$ hours from last seen healthy. There was no evidence of heterogeneity of treatment effect between the early presenters and subjects enrolled in the extended time window $(P=.134$, likelihood ratio test). Table 1 shows differences in demographics, baseline characteristics, and workflow between the intervention $(n=33)$ and control $(n=26)$ arms of subjects within the late time window. Patients in the control arm were more likely to receive intravenous alteplase; otherwise, the population characteristics were similar.

Clinical outcomes in late-window subjects are summarized in Table 2 and the Figure. A treatment effect favoring intervention is seen across all clinical outcomes. In this subgroup, intervention was superior to the best medical therapy for NIHSS $0-2$ at 90 days ( $45.5 \%$ versus $13.6 \%, P=.019$ ). The absolute risk difference favoring intervention was $19.3 \%$ on the mRS $0-2$ at 90 days, and the shift analysis (proportional odds model) favored intervention (adjusted common $\mathrm{OR}=2.61$; $95 \%$ CI, 0.9-7.8). A higher rate of all types of ICH (including petechial hemorrhage) was noted in the intervention arm (Table 3), but not of symptomatic ICH. 
Table 2: Clinical outcomes and treatment effect in subjects in the ESCAPE trial with last seen healthy to randomization time of $>5.5$ hours

\begin{tabular}{lccccc}
\hline \multicolumn{1}{c}{ Outcome } & $\begin{array}{c}\text { Intervention } \\
(\boldsymbol{n}=\mathbf{3 3 )}\end{array}$ & $\begin{array}{c}\text { Control } \\
(\boldsymbol{n}=\mathbf{2 6})\end{array}$ & $\begin{array}{c}\text { Risk Difference } \\
\text { (Absolute) }\end{array}$ & $\begin{array}{c}\text { Risk Ratio } \\
\boldsymbol{P} \text { Value }\end{array}$ & $\begin{array}{c}\text { Unadjusted (95\% Cl) } \\
\text { Uns }\end{array}$ \\
\hline mRS at 90 days, (median) (IQR) & $3(3)$ & $4(3)$ & - & $.029^{\mathrm{a}}$ & - \\
mRS 0-2 at 90 days & $48.5 \%(16 / 33)$ & $29.2 \%(7 / 24)$ & $19.3 \%$ & .178 & $1.7(0.8-3.4)$ \\
mRS 0-1 at 90 days & $39.3 \%(13 / 33)$ & $20.1 \%(5 / 24)$ & $18.6 \%$ & .161 & $1.89(0.8-4.6)$ \\
NIHSS score 0-2 at 90 days & $45.5(15 / 33)$ & $13.6(3 / 22)$ & $31.8 \%$ & .019 & $3.33(1.1-10.2)$ \\
ICH any (all types) & $48.5 \%(16 / 33)$ & $11.5 \%(3 / 26)$ & $36.9 \%$ & .004 & $4.2(1.4-12.9)$ \\
ICH symptomatic & $0 \%$ & $0 \%$ & $0 \%$ & 1.000 & - \\
mTICl 2b-3 (EVT group) or mAOL 2-3 (control group) & $87.5 \%(28 / 32)$ & $13.0 \%(3 / 23)$ & $74.5 \%$ & - & - \\
\hline
\end{tabular}

Note:- mTICI indicates modified Thrombolysis in Cerebral Infarction score; mAOL, modified Arterial Occlusive Lesion score; EVT, endovascular treatment.

a Parametric test of medians.

${ }^{\mathrm{b}}$ Reperfusion assessed as $\mathrm{mTICI} 2 \mathrm{~b}-3$ at end of EVT in the intervention group or as recanalization with mAOL score 2-3 on repeat CTA in the control group.

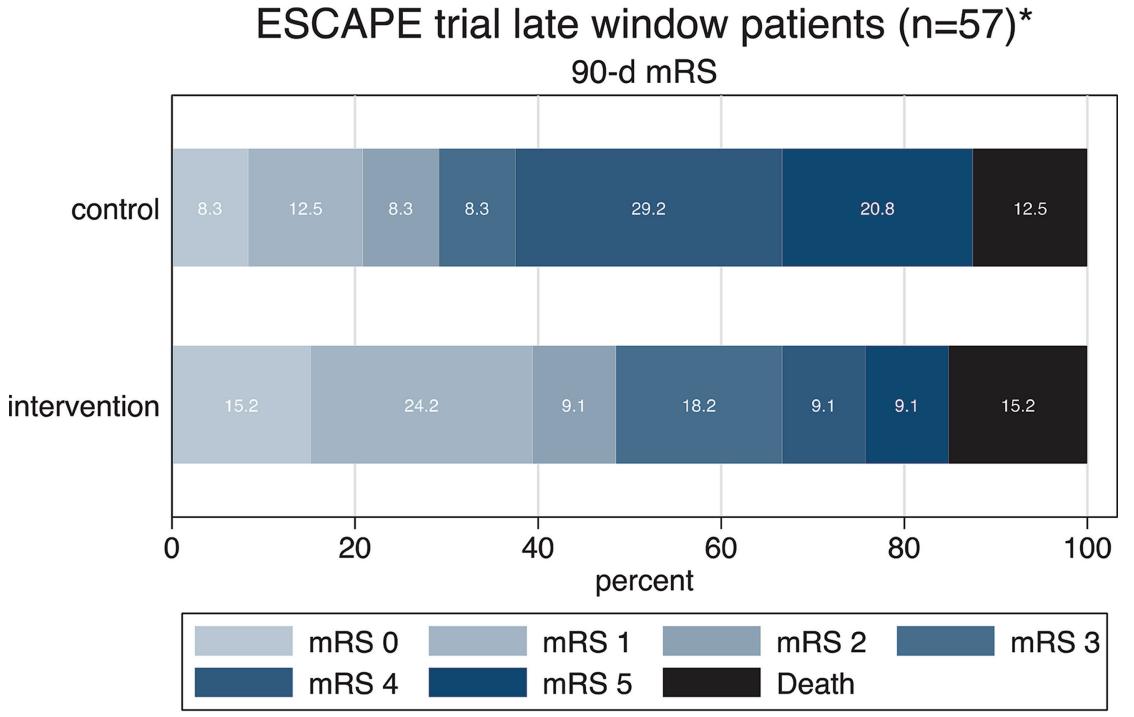

*2 patients had missing outcomes

adjusted $\mathrm{cOR}=2.61,95 \% \mathrm{Cl}$ 0.9-7.8 from proportional odds model
FIGURE. Ninety-day mRS distribution in the intervention $(n=33)$ and the control $(n=26)$ arms of the ESCAPE trial in subjects randomized $>5.5$ hours from last seen healthy. cOR indicates common odds ratio.

Table 3: Distribution of intracerebral hemorrhage using the ECASS radiologic classification on follow-up imaging in subjects with last seen healthy to randomization of $>5.5$ hours in the ESCAPE trial ${ }^{\mathrm{a}}$

\begin{tabular}{lcc}
\hline \multicolumn{1}{c}{ ICH Type } & Intervention $(\boldsymbol{n}=\mathbf{3 3})$ & Control $(\boldsymbol{n}=\mathbf{2 6})$ \\
\hline $\mathrm{HI}-1$ & $18.1 \%(6)$ & $3.8 \%(1)$ \\
$\mathrm{HI}-2$ & $24.2 \%(8)$ & $7.7 \%(2)$ \\
$\mathrm{PH}-1$ or $\mathrm{rPH}-1$ & $3.0 \%(1)$ & $0(0)$ \\
$\mathrm{PH}-2$ or $\mathrm{rPH}-2$ & $3.0 \%(1)$ & $0(0)$ \\
None & $51 \%(17)$ & $88.5 \%(23)$ \\
\hline
\end{tabular}

Note:- $\mathrm{HI}$ indicates hemorrhagic infarction; $\mathrm{PH}$, parenchymal hematoma; $\mathrm{rPH}$, remote parenchymal hematoma.

${ }^{\text {a }}$ Composite $P$ value $=.029$

\section{DISCUSSION}

The ESCAPE trial enrolled a small number of subjects in late time windows but showed no evidence of heterogeneity of treatment effect in subjects between the early and late time windows. In the late time window population, all clinical outcomes showed trends favoring the intervention arm, consistent with the recent metaanalyses of the endovascular trials. ${ }^{3,4}$

The ESCAPE trialists adopted a 2-stage screening paradigm to identify subjects for enrollment. The 12-hour window identified the population sampling frame and was an arbitrary threshold determined by consensus at the time of the study design. These subjects were then imaged using a CT/CTA metric to identify individuals for enrollment. Imaging served as a marker of favorable brain physiology instead of time. ${ }^{10}$ This was a pragmatic choice because the patient is often unaware of stroke-onset time or is unable to communicate it clearly. Epidemiologic studies suggest that 1 of every 3 patients with stroke may either wake up with symptoms or have unwitnessed onset, and this proportion may increase with an aging population. ${ }^{11-14}$ Patients with unwitnessed stroke onset may have a last known well time many hours before or immediately proximate to the time of stroke recognition. Among this group, 2 types of patients can be identified. Both patients with a true recent infarct onset and patients with good collaterals and slow infarct progression can be identified as ideal therapy candidates. ${ }^{15,16}$ The change to a physiologic paradigm of using time windows to select which populations to screen and then imaging to select those eligible for acute treatment is actively supported by these results.

Because late presenters, on average, are more likely to have larger infarcts with more severe parenchymal and endothelial damage, these patients may be at higher risk of hemorrhage than early presenters. Our analysis showed an increased risk of occurrence of all ICHs in late presenters in the intervention group compared with best medical therapy; however, this risk applied to the clinically silent hemorrhagic infarction types and not to the clinically relevant parenchymal hematoma category. There was no difference in clinically defined symptomatic ICH.

Our study is limited by a small sample size and the post hoc nature of our analysis, but a major strength is that findings arise from a carefully controlled prospective randomized trial. Recently, the DAWN trial implemented an image-based patient selection with $\mathrm{CT} / \mathrm{MR}$ imaging perfusion to provide randomized controlled trial data to support endovascular treatment in the extended time window and to further support the paradigm of using imaging selection of patients for treatment. 


\section{CONCLUSIONS}

While the results of the DAWN study are not yet published, some limited comparisons can be made with recent preliminary data. Among the 206 patients enrolled in the DAWN trial, the median age was 72 and 73 years in the intervention and control arms, respectively, and the median baseline NIHSS of 17 in both treatment groups was like that in our analysis. The last seen healthy time to randomization was greater in the DAWN trial (13.4 \pm 4.1 hours; median, 12.2 hours in the treatment arm; and $13.0 \pm 4.5$ hours; median, 13.2 hours in the control arm). ${ }^{17}$ The reported weighted-based coprimary outcome of the mean mRS was 5.5 versus 3.4 in the control and intervention groups, respectively, in DAWN. ${ }^{5}$ Although not directly comparable with our post hoc subgroup analysis, the positive signal seen in our results appears to be supported by this randomized controlled trial data. We await the formal publication of the DAWN and DEFUSE 3 trials to provide further opportunity for comparison with these data.

\section{ACKNOWLEDGMENTS}

The ESCAPE trialists would like to acknowledge the contribution of Dr Cheemun Lum, a key member of the ESCAPE trial team at the University of Ottawa and a dedicated and talented neurointerventionalist, who passed away suddenly during the completion of this work.

Disclosures: Jeremy L. Rempel—UNRELATED: Consulting Fee or Honorarium: Memorial University, Comments: speaking honorarium. Ashfaq Shuaib-UNRELATED: Board Membership: Canadian Stroke Consortium*; Employment: University of Alberta. David Williams—RELATED: Grant: University of Calgary, Comments: I was a site investigator (Ireland) for the ESCAPE study*; Support for Travel to Meetings for the Study or Other Purposes: University of Calgary, Comments: I was a site investigator (Ireland) for the ESCAPE study and was supported to attend investigator meetings*; UNRELATED: Board Membership: Boehringer Ingelheim, Bayer, Bristol Myers Squibb, Daiichi Sankyo, Comments: member of the Advisory Board on the safe use of novel anticoagulants. Daniel F. Roy—RELATED: Grant: University of Calgary, Comments: Angiography Core Lab for the ESCAPE trial. Alexander Y. Poppe-RELATED: Grant: University of Calgary, Comments: fees paid per patient enrolled for participation of our center in the ESCAPE trial*; UNRELATED: Board Membership: Bayer, Bristol-Myers Squibb-Pfizer, Comments: Advisory Boards 2016; Grants/Grants Pending: CaSTOR, The Canadian Stroke Trials for Optimized Results, Comments: catalyst grant for developing a study network on tandem carotid lesions in acute stroke; Payment for Lectures Including Service on Speakers Bureaus: Medtronic, Comments: speaker fees 2016; Payment for Development of Educational Presentations: EMD Serono, Comments: examiner in mock exam for neurology residents. Tudor G. Jovin—UNRELATED: Consultancy: Neuravi, Codman Neurovascular, Comments: Neuravi, Steering Committee member; Codman Neurovascular, Data and Safety Monitoring Board member; Stock/Stock Options: Anaconda, Silk Road, Route 92, Blockade Medical; Travel/Accommodations/Meeting Expenses Unrelated to Activities Listed: Stryker* (Principal Investigator DAWN). Thomas Devlin—RELATED: Grant: Medtronic, Comments: research support; UNRELATED: Consultancy: BrainsGate, San Bio, Ornim Medical, Daiichi Sankyo, Comments: research support*; Payment for Lectures Including Service on Speakers Bureaus: Medtronic, Comments: speakers bureau.* Michael D. Hill—RELATED: Grant: Medtronic, University of Calgary, Alberta Innovates, Heart and Stroke Foundation, Canadian Institutes of Health Research, Alberta Health Services, Comments: grants or support-in-kind to the University of Calgary for the ESCAPE trial*; UNRELATED: Board Membership: Canadian Neuroscience Federation, Comments: volunteer governance board for a not-for-profit organization; Consultancy: Merck, Comments: remuneration for clinical trial adjudication of outcomes panel; Grants/Grants Pending: Medtronic, Comments: grant support for the HERMES collaboration; Stock/ Stock Options: Calgary Scientific, Comments: stock ownership in a Calgary imaging and data company. Philip A. Barber-UNRELATED: Consultancy: Ablynx Pharmaceutical*; Employment: University of Calgary; Grants/Grants Pending: Heart and Stroke Foundation of Canada*. Daniela lancu-RELATED: Grant, Comments: ESCAPE Trial*. Bijoy K. Menon—RELATED: Grant: Covidien*; UNRELATED: Patents (Planned, Pending or Issued), Comments: US patent pending, patent on systems of triage for stroke; Stock/Stock Options: Quikflo Health. Blaise W. Baxter-UNRELATED: Consultancy/Speakers Bureau: Penumbra, Medtronic, Stryker, Pulsar, Route 92; Patents (Planned, Pending or Issued): Advanced Catheter Therapies, Comments: Patent US8622992, no royalties. Mayank GoyalRELATED: Grant: Medtronic, Comments: part funding of the ESCAPE trial, funding for HERMES collaboration*; Consulting Fee or Honorarium: Medtronic, Comments: consulting fee for design and conduct of SWIFT PRIME trial; UNRELATED: Consultancy: Stryker, MicroVention, Ablynx, Comments: for educational activities and product advice; Patents (Planned, Pending or Issued): GE Healthcare, MicroVention, Comments: licensing agreement for systems of stroke diagnosis and systems of intracranial access. Donald F. Frei-UNRELATED: Consultancy: Stryker, MicroVention, Penumbra; Payment for Lectures Including Service on Speakers Bureaus: Stryker, MicroVention, Penumbra; Stock/Stock Options: Penumbra. Donatella Tampieri-UNRELATED: Consultancy: Canadian Medical Protective Association; Grants/Grants Pending: Fonds de recherche du Québec. * Andrew M. Demchuk—RELATED: Grant: Medtronic, Comments: unrestricted grant to support enrollment and coordination of the ESCAPE trial*; Consulting Fee or Honorarium: Medtronic, Comments: honoraria for Continuing Medical Education events. Frank L. Silver-UNRELATED: Consultancy: Boehringer Ingelheim Canada, Comments: National Coordinator, REPECT ESUS clinical trial. *Money paid to the institution.

\section{REFERENCES}

1. Powers WJ, Derdeyn CP, Biller J, et al; American Heart Association Stroke Council. 2015 American Heart Association/American Stroke Association Focused Update of the 2013 Guidelines for the Early Management of Patients with Acute Ischemic Stroke Regarding Endovascular Treatment: A Guideline for Healthcare Professionals from the American Heart Association/American Stroke Association. Stroke 2015;46:3020-35 CrossRef Medline

2. Casaubon LK, Boulanger JM, Glasser E, et al; Heart and Stroke Foundation of Canada Canadian Stroke Best Practices Advisory Committee. Canadian Stroke Best Practice Recommendations: Acute Inpatient Stroke Care Guidelines, update 2015. Int J Stroke 2016;11: 239-52 CrossRef Medline

3. Goyal M, Menon BK, van Zwam WH, et al; HERMES collaborators. Endovascular thrombectomy after large-vessel ischaemic stroke: a meta-analysis of individual patient data from five randomised trials. Lancet 2016;387:1723-31 CrossRef Medline

4. Saver JL, Goyal M, van der Lugt A, et al; HERMES collaborators. Time to treatment with endovascular thrombectomy and outcomes from ischemic stroke: a meta-analysis. JAMA 2016;316:1279-88 CrossRef Medline

5. Jovin TG, Nogueira RG. Dawn in full daylight. In: Proceedings of the 3rd European Stroke Organisation Conference, Prague, Czech Republic; May 16-18, 2017

6. Goyal M, Demchuk AM, Menon BK, et al; ESCAPE Trial Investigators. Randomized assessment of rapid endovascular treatment of ischemic stroke. N Engl J Med 2015;372:1019-30 CrossRef Medline

7. Demchuk AM, Goyal M, Menon BK, et al; ESCAPE Trial Investigators. Endovascular treatment for Small Core and Anterior circulation Proximal occlusion with Emphasis on minimizing CT to recanalization times (ESCAPE) trial: methodology. Int J Stroke 2015; 10:429-38 CrossRef Medline

8. Menon BK, Sajobi TT, Zhang Y, et al. Analysis of workflow and time to treatment on thrombectomy outcome in the endovascular treatment for small core and proximal occlusion ischemic stroke (ESCAPE) randomized, controlled trial. Circulation 2016;133: 2279-86 CrossRef Medline

9. Hacke W, Kaste M, Fieschi C, et al; Second European-Australasian Acute Stroke Study Investigators. Randomised double-blind placebo-controlled trial of thrombolytic therapy with intravenous alteplase in acute ischaemic stroke (ECASS II). Lancet 1998;352: 1245-51 CrossRef Medline

10. Hill MD, Goyal M, Demchuk AM, et al. Ischemic stroke tissue-window in the new era of endovascular treatment. Stroke 2015;46: 2332-34 CrossRef Medline

11. Thomalla G, Gerloff C. Treatment concepts for wake-up stroke and stroke with unknown time of symptom onset. Stroke 2015;46: 2707-13 CrossRef Medline

12. Nadeau JO, Fang J, Kapral MK, et al; Registry of the Canadian Stroke 
Network. Outcome after stroke upon awakening. Can J Neurol Sci 2005;32:232-36 Medline

13. Bal S, Bhatia R, Shobha N, et al. Stroke-on-awakening: Safety of CT-CTA based selection for reperfusion therapy. Can J Neurol Sci 2014;41:182-86 CrossRef

14. Hill MD, Kenney C, Dzialowski I, et al. Tissue Window in Stroke Thrombolysis study (TWIST): a safety study. Can J Neurol Sci 2013; 40:17-20 CrossRef Medline

15. Menon BK, Qazi E, Nambiar V, et al; Interventional Management of Stroke III Investigators. Differential effect of baseline computed to- mographic angiography collaterals on clinical outcome in patients enrolled in the Interventional Management of Stroke III trial. Stroke 2015;46:1239-44 CrossRef Medline

16. Hwang YH, Kang DH, Kim YW, et al. Impact of time-to-reperfusion on outcome in patients with poor collaterals. AJNR Am J Neuroradiol 2015;36:495-500 CrossRef Medline

17. Nogueira RG, Jadhav AP, Haussen DC, et al; DAWN Trial Investigators. Thrombectomy $\mathbf{6}$ to 24 hours after stroke with a mismatch between deficit and infarct. N Engl J Med 2017 Nov 11. [Epub ahead of print] CrossRef Medline 